\title{
Minería, resistencia y represión en Honduras: entre la ley y la impunidad
}

\author{
Nick Middeldorp
}

\author{
Wageningen University and Research Centre, Wageningen, Países Bajos \\ nick.middeldorp@gmail.com
}

\begin{abstract}
Resumen: Esta artículo, basado en una investigación etnográfica de 6 meses entre mayo y noviembre del 2013, analiza la conflictividad social causada por la expansión de la frontera minera en Honduras: el movimiento antiminero logra movilizar a las comunidades rurales para declarar sus municipios libre de minería; mientras tanto, la industria minera puede circunvenir el derecho legal a la consulta a través de la criminalización de protesta y el uso de violencia. Este artículo plantea serias preocupaciones sobre esta tendencia e indica que los movimientos sociales son capaces de adaptarse y desarrollar resistencias exitosas en ambientes políticamente y jurídicamente complejos.
\end{abstract}

Palabras clave: Honduras; minería; movimientos sociales; conflicto social; consulta.

\section{Mining, resistance, and repression in Honduras: between law and lawlessness}

Abstract: The expansion of the mining frontier in Honduras provokes resistance of an anti-mining movement, which mobilizes rural communities to declare their municipalities free of mining. Meanwhile, the mining industry can circumvent the legal right to consultation by the criminalization of protest and the use of violence. This article plants serious concerns about this tendency, but also shows how social movements can adapt and develop successful resistance in complex political and juridical environments. Keywords: Honduras; mining; social movements; social conflict; consultation.

Cuadernos de Antropología

Julio-Diciembre 2016, 26(2), 69-89

DOI: $10.15517 /$ cat.v26i2.26488

Recibido: 23-02-2016 / Aceptado: 26-05-2016 / Publicado: 13/12/2016

Revista del Laboratorio de Etnología María Eugenia Bozzoli Vargas

Escuela de Antropología, Universidad de Costa Rica

http://revistas.ucr.ac.cr/index.php/antropologia

ISSN 2215-356X

cc) (7) Cuadernos de Antropología está bajo una licencia

EY NC SA Creative Commons Attribution-NonCommercial-ShareAlike 3.0 


\section{Introducción}

En el debate sobre el papel de las industrias extractivas en procesos de desarrollo, varios académicos mantienen que el modelo económico extractivista, implementado por diversos gobiernos latinoamericanos, sea de izquierda o derecha, representa una "acumulación por despojo", también conocido como posesión por desposesión por David Harvey (2004), del inglés possession by dispossession: un modo de acumulación que deja sus impactos en los niveles locales y globales, sosteniendo y reforzando la desigualdad local y global (Acosta, 2011; Bebbington, 2012; Svampa, 2011). En las sociedades latinoamericanas, el extractivismo ha provocado el surgimiento de grupos de protesta, como los conformados por las ONG de derechos humanos o de ambiente, así como movimientos sociales ambientalistas e indígenas. Esta investigación clarifica este conflicto social generado por la expansión de la industria extractiva en Honduras, un país poco investigado, pero en la coyuntura de dar un fuerte impulso a la minería con la implementación de una política extractivista neoliberal.

Después del Huracán Mitch, en 1998 - un desastre natural que dejó una significativa destrucción en el país- el gobierno hondureño puso en marcha una nueva política. Una nueva ley de minería, basada en la ley minera de Chile de 1983, fue redactada rápidamente y fue aprobada por el congreso nacional después de un solo debate, en forma de "doctrina de choque" (Moore, 2012). Su intención era fomentar un auge minero en un país con reservas vírgenes de minerales. La ley de minería de 1998 y el establecimiento de dos minas canadienses a cielo abierto de lixiviación con cianuro provocaron el nacimiento de un movimiento antiminero. Su lucha obtuvo importantes avances, y se logró poner un alto por completo a la expansión de la industria minera en Honduras.

Poco tiempo después, sin embargo, el presidente Zelaya fue expulsado por el golpe de estado en junio del 2009, y el gobierno posgolpe comenzó a otorgar nuevas concesiones mineras, con la intención de combatir la crisis económica agravada por el golpe y reformar la economía hondureña. Los gobiernos posgolpes del Partido Nacional, desde noviembre del 2013 liderado por el presidente Juan Orlando Hernandez, consideran la expansión de la industria extractiva como la punta de lanza del plan nacional de desarrollo. Para facilitar la expansión esta industria, el nuevo régimen -estimulado por cabildeadores del gobierno canadiense y la industria minera transnacional (Gordon y Webber, 2011; Moore, 2012)- redactó una nueva ley de minería en el 2012. A pesar de nuevas protestas por numerosas organizaciones de sociedad civil y la oposición política, la nueva ley entró en vigencia el día 23 de abril 2013.

Como respuesta a esta segunda expansión de explotación minera en Honduras, los oponentes a la minería están movilizándose de nuevo para enfrentar las implicaciones de la nueva ley. No obstante, la situación de derechos humanos es precaria, y los activistas de todo tipo son especialmente vulnerables (Monge, 2013; Global Witness, 2015). Por ejemplo, en marzo del 2014, la policía militar intervino para liberar una carretera bloqueada por las comunidades de El Níspero frente la instalación de una mina de óxido de hierro a cielo abierto. La confrontación fue seguida por el brutal asesinato de Rigoberto López Hernández en mayo 
del mismo año. A Hernández - miembro del Movimiento Ambiental Santabarbarense y trabajando en El Níspero- le degollaron y le cortaron la garganta y le cortaron la lengua antes de que su cuerpo fuera dejado en un espacio público, destinado a ser encontrado (Rights Action, 2014).

Este artículo comienza, en primer lugar, con una explicación de la metodología aplicada en esta investigación y sigue con la base teórica del estudio: el empuje de la frontera de explotación de recursos naturales y el análisis de los movimientos sociales. Segundo, entra en detalle sobre el contexto histórico de la resistencia contra la minería en Honduras -indispensable para comprender la situación actual. Continuando, se presenta un estudio de caso, para después discutir las prácticas del movimiento antiminero, con enfoque en el proceso de declarar los municipios "libres de minería". En la última sección, se muestra unas conclusiones relevantes.

\section{Metodología de investigación}

En esta sección, se presenta en detalle la metodología de investigación. Este artículo está basado en una investigación etnográfica en Honduras, realizada durante un período de 6 meses entre mayo y noviembre del 2013 -justamente después de la aprobación de la nueva Ley de Minería en abril de ese año. El acceso al "campo" fue negociado con anticipación: desde el comienzo de la investigación, yo estaba involucrado en Asonog, una ONG hondureña con base en Santa Rosa de Copán que forma parte del movimiento antiminero hondureño. Mi asociación con Asonog me dio una entrada perfecta: podía contar con su apoyo logístico y tener acceso a las comunidades rurales afectadas por la minería; además, otras organizaciones dentro del movimiento me podían recibir con un grado de confianza. Esta facilidad contrasta con la dificultad que tenía en obtener acceso a las instituciones relevantes del Estado y las empresas mineras, pues debía tener cuidado en no mencionar mi afiliación a la ONG.

La investigación etnográfica es particularmente útil para este tipo de trabajos porque tiene el objetivo de llegar a una comprensión de las prácticas y las nociones de un grupo más o menos acotado dentro de un contexto general, prestando atención a las características alrededores sociales, políticos y económicos que lo rodean (Eriksen, 2004; Van Maanen, 1988). Incluidos en la metodología del trabajo de campo etnográfico están métodos como entrevistas formales e informales, la observación participante, y el análisis de documentos. En combinación, estos métodos me permitieron descubrir la historia del movimiento, las diferentes percepciones y marcos discursivos, las acciones que se emprenden; y hacer sentido de los obstáculos enfrentados por el movimiento.

Asonog y yo establecimos una lista de informantes potenciales (personas y organizaciones) para entrevistar. A lo largo del país, realicé entrevistas con ambientalistas, representantes de las ONG nacionales e internacionales, movimientos sociales, empresas mineras, y del Estado. Al final, ejecuté 37 entrevistas a profundidad, que fueron preparadas de antemano mediante una "pauta de entrevista": una lista de preguntas 
abiertas que se puede alterar durante la entrevista (Heldens y Reysoo, 2005). Similarmente, durante encuentros y capacitaciones comunitarias, tuve la oportunidad de hablar con numerosos activistas y miembros de las comunidades. Algunos de mis informantes son representantes del Estado, conocidos a nivel nacional, o ambientalistas que usan su publicidad internacional como estrategia de seguridad: sus nombres están mencionados en este artículo. Sin embargo, por razones de seguridad, también he usado seudónimos y omitido nombres reales. Todas las entrevistas a profundidad y la mayoría de las entrevistas informales son el resultado de una muestra deliberada. La mayoría de los informantes fueron contactados de antemano; sin embargo, siempre que la oportunidad se presentó, usé métodos de muestreo de oportunidad y "bola de nieve", especialmente trabajando en las comunidades rurales. No recibí una respuesta de ANAMIMH ${ }^{1}$, la plataforma que representa las empresas mineras transnacionales a nivel nacional, a pesar de escribir varios correos y hacer numerosos llamadas.

La observación participante es el último método que utilicé. Simplemente definido, la observación participante implica “observar y participar en la acción social mientras está ocurriendo" (Lichterman, 1998, p. 41). En el contexto de investigar activismo, "los observadores-participantes pueden descubrir qué tradiciones, símbolos y relatos hacen que el activismo sea significativo mientras está ocurriendo en la vida diaria" (Lichterman 1998, p. 401 [énfasis en el original]). En círculos de activistas, la observación participante también puede cerrar la brecha entre activista e investigador -aunque esto trae sus complicaciones. Con Asonog y la aliada MIGR² participé en capacitaciones comunitarias en Santa Rosa de Copán, 6 de mayo, Intíbuca, Valle de Siria, Danlí, Catacamas y Trujillo. También realicé visitas a las comunidades en la mina de San Andrés en Copán, y a comunidades a lo largo de los departamentos de Atlántida, Colón, y Yoro; además, participé en foros regionales sobre "la defensa de los bienes naturales" en Honduras y en sus países vecinos Nicaragua y El Salvador.

La confianza y la "posicionalidad" -ambas parcialmente formadas por la actitud y las opciones en el campo- son dos dimensiones que afectan el curso de investigación y la información recibida. En este sentido, mi afiliación con una organización antiminera fue útil para establecer contactos y ganar confianza. No obstante, el tema de minería es políticamente sensible y, como es comentado por Sluka (1990), "mientras más político o controversial sea el sujeto que uno investiga, más probable es que uno sea sospechosos de sesgo y partidismo" (p. 123). Entonces, algunos momentos de investigación requerían una representación estratégica: me avisaron no mencionar mi afiliación con Asonog durante entrevistas con representantes del Estado o las empresas mineras, y, por lo tanto, los contactaba con el discurso de investigar cómo la minería puede contribuir al desarrollo de Honduras.

En conformidad con Golafshani (2003), argumento que la calidad de la investigación cualitativa tiene que ser juzgada por su integridad, derivada de los métodos de investigación aplicados en el campo y des-

1 Asociación Nacional de Mineras Metálicas de Honduras

2 Mesa para la Incidencia de Gestión del Riesgo

Cuadernos de Antropología 2016, 26(2), 69-89 / ISNN 2215-356X

http://revistas.ucr.ac.cr/index.php/antropologia 
pués analizados. La triangulación, el uso de métodos mixtos, son de vital importancia aquí. La investigación etnográfica, por su naturaleza, emplea diferentes métodos: entrevistas formales e informales, observación participante y análisis de documentos. Aparte de triangulación, el trabajo de campo y el análisis permitieron desplegar numerosos momentos de reflexión en conjunto con Asonog sobre los resultados de la presente investigación, para así lograr una validez interna.

\section{Marco teórico: extractivismo y movimientos sociales}

El modelo de desarrollo basado en minerales, como el fomentado por el gobierno hondureño, se define como extractivismo: "el patrón de acumulación basado en la sobre-explotación de los recursos naturales, muchos no-renovables, y la expansión de las fronteras hacia los territorios anteriormente considerados no-productivos" (Svampa, 2011, p. 2). Aplicando el argumento de Peluso y Lund (2011) sobre control de territorio, esta investigación argumenta que la expansión de la industria minera arremete contra la frontera de recursos -en esta arremetida se utiliza distintas estrategias para establecer un control territorial. E1 territorio está reclamado -y controlado- por los actores y procesos que en conjunto forman un "complejo extractivista": una configuración de fuerzas institucionales y político-económicas contingenciales (Watts y Peluso, 2014), en las que sobresalen las compañías mineras, sus grupos de lobby, y las instituciones del Estado que proveen el marco legal e institucional para estas compañías.

Peluso y Lund (2011) han identificado diversos mecanismos interrelacionados para reclamar y controlar territorios: cercamiento, alianzas, legalización y violencia. El cercamiento se refiere a ambas, a la separación física del territorio reclamado (ej. poniendo alambre de púas), así como los alambres institucionales que niegan y penalizan el acceso de intrusos. La creación de alianzas institucionales y compromisos entre actores del Estado, empresa y sociedad civil extiende el control social y político. La "legalización" no solamente se refiere a la institucionalización de la propiedad privada, sino también a la aplicación (selectiva) de la ley para legalizar (y legitimar) el reclamo. Violencia, incluyendo la militarización y el uso de terror, también puede estar incluida en el repertorio de la gobernanza de recursos y territorios.

Este proceso causa una pérdida de control por parte de las comunidades ahí asentadas, conceptualizado como posesión por desposesión o acumulación por despojo: un concepto introducido por Harvey en el 2004. Se refiere a la privatización de recursos naturales como aguas y tierras, el desalojo forzado de comunidades de sus territorios comunales, la transformación de varias formas de derechos de propiedad común en regímenes privados, y la supresión de formas alternativas de producción (Harvey, 2004). Sin duda, la expulsión forzada es la forma más visible y cruda de despojo (Sosa, 2012), que, en combinación con políticas de recompensación fracasadas, marginaliza aún más a la población rural pobre (Joker, 2004). Sin embargo, la noción de despojo va más allá: por ejemplo, incluye la desposesión del agua, por el hecho de que la minería compite con la agricultura local por este líquido, mientras las autoridades tienden a favorecer a la minería (Budds y Hinojosa, 2012; Perreault, 2013). El despojo es tanto un sentimiento como un proceso 
material: implica un sentimiento de pérdida de control sobre el espacio, los recursos "propios" de la comunidad y su capacidad de ejercer autodeterminación. Una concesión de exploración ya puede provocar una percepción de inseguridad y riesgo (Bebbington, Bebbington y Bury, 2010, p. 16): la gente viviendo sobre un territorio concesionado sabe que cualquier día podrían tener que abandonar sus hogares. Como anotado por Coronel (2013), el miedo por la posible contaminación del agua también juega un papel importante.

Como lo señalado por Harvey (2004), el Estado, con su "monopolio de la violencia y sus definiciones de la legalidad" (p. 113), tiene una posición clave en promover el proceso de posesión por desposesión. A lo largo del continente latinoamericano, la acumulación por despojo es activamente enfrentada por movimientos sociales (Bebbington et al., 2008). En esta investigación, el concepto de movimiento social está definido, según Melucci y Avitser (2000) como: "una forma de acción colectiva que tiene tres características: 1) la creación de solidaridad, 2) la representación pública del conflicto existente, y 3) la ruptura de los límites de compatibilidad con el sistema en que la acción ocurre" (p. 518). De esta forma, en este contexto, la creación de solidaridad se refiere al aspecto de colaboración y consolidación de una serie de grupos o individuos en un movimiento más o menos delimitado. Además, la representación pública del conflicto existente: los actores involucrados en el movimiento activa y estratégicamente (re)presentan un conflicto o lucha en el ámbito público. Asimismo, la última característica se refiere al contexto de fondo que provee la necesidad de movilización: si se pudiera resolver el asunto por otros canales sociales, políticos o institucionales (ej. por votación), no sería necesario organizarse en un movimiento. Cuando estas medidas no bastan para lograr su objetivo, organizarse en un movimiento social puede ser una ruta alternativa.

Esta investigación utiliza un enfoque cultural del análisis de los movimientos sociales. Este enfoque argumenta que se puede considerar a los movimientos sociales como vehículos en los cuales las personas luchan para satisfacer sus necesidades colectivas (Zibechi, 2003); expresan su autonomía y revalúan su identidad por medio de rituales de solidaridad (Melucci y Avitser, 2000). Según el enfoque cultural, no es simplemente una búsqueda racional de ciertos objetivos lo que da origen a los movimientos sociales, sino la identidad compartida y la toma de sentido.

Lo que constituye un movimiento social siempre es una combinación de ciertos aspectos y objetivos. Para comenzar, un sentido de exclusión o privación está en el corazón del movimiento (Hellman, 1992): sea este la negación de justicia o la verdad, o la exclusión estructural de grupos sociales enteros. Un movimiento siempre persigue un interés colectivo expresando cierta identidad y valoración, formando una fuerza social o política que enfrenta los narrativos y las prácticas dominantes, ofreciendo versiones alternativas de la verdad. Según lo escrito por Yagenova (2010):

Un aspecto clave entonces es enfrentar el poder hegemónico con una correlación de fuerzas de poderes contra-hegemónicos que trascienden el cuestionamiento del sistema hacia la construcción de formas alternativas de vida. En este sentido, son los movimientos sociales quienes mediante su amplio repertorio de acciones colectivas 
construyen pensamiento crítico y prácticas sociales que abonan a concebir modelos alternativos (p. 17).

En este sentido, un movimiento social no es solamente un vehículo por el cual las personas expresan colectivamente su identidad y preocupaciones, sino también uno por el cual las personas tratan de enfrentar y superar la dominación (Touraine, 2004). En cuanto a la minería, han surgido movimientos para responder a los riesgos (tanto reales como percibidos) para los livelihoods (medios de subsistencia) y la autodeterminación por medio de la acción colectiva, normalmente con la intención de detener la minería (resistencia) o de cambiar las condiciones de la minería (reforma).

En estos conflictos mineros, los intereses divergentes son particularmente altos, como lo observado por Bebbington (2012, p. 5): "la industria extractiva produce, al mismo tiempo riqueza y destrucción increíble"; altas ganancias financieras versus la pérdida de medios de subsistencia, desalojo y destrucción ambiental. Las luchas antimineras surgen de diferentes perspectivas sobre el desarrollo: por un lado, la versión del Estado y la industria; y por otro, la versión o las versiones de los movimientos de base. Según Bebbington y Valencia (2007), el conflicto social resultante es un precursor necesario para lograr un cambio progresivo social e institucional en cuanto a la minería. Entonces, los conflictos mineros son tanto luchas por los recursos como luchas por el significado: son arenas metafóricas donde se enfrentan ideas diferentes sobre el desarrollo, el papel de las comunidades locales, o la valorización del medioambiente. Los movimientos antimineros enfrentan el extractivismo, cuestionan su lógica y proveen una alternativa de base. En este proceso de acción colectiva, se construye nuevos sentidos y nuevos valores.

\section{Contexto histórico de la resistencia contra la minería en Honduras}

La Ley de minería de 1999 (República de Honduras, 1999) permitió la instalación de dos minas industriales, la mina de San Andrés en el departamento de Copán y la de San Martín en el Valle de Siria, departamento de Francisco Morazán, ambas de propiedad canadiense que utilizan el método de lixiviación con cianuro a cielo abierto para extraer oro. Las dos operaciones mineras causaron una ruptura en la vida social y graves impactos ambientales, particularmente la mina San Martín de la empresa Goldcorp, donde se ha registrado serios daños a la salud humana (Bianchini, 2006). La resistencia comunitaria en las zonas afectadas, particularmente del Comité Ambiental de Valle de Siria (CAVS), fue respaldada por las ONG como ASONOG, Caritas, y la Asociación Madre Tierra: el nacimiento de un movimiento antiminero.

Las organizaciones involucradas en la lucha frente a estas minas convergieron cada vez más en un solo movimiento. En el 2005, un recurso legal tuvo como resultado la declaración de inconstitucionalidad, por parte de la Corte Suprema de Justicia, de 13 artículos de la Ley de Minería (República de Honduras, 1999); entre otros, el régimen de impuestos y los artículos que permitían la expropiación forzada. Mientras tanto, el movimiento Alianza Cívica por la Democracia (ACD) obtuvo suficiente impulso para presionar al 
gobierno central a través de movilizaciones y bloqueos a gran escala. Como resultado, se detuvo el otorgamiento de nuevas concesiones mineras y bajo fuerte presión del movimiento, la mina de San Martín de la empresa Goldcorp cerró sus operaciones en el 2008. Además, el entonces presidente Manuel Zelaya creó una comisión para redactar una nueva ley de minería que aumentaría los impuestos; prohibiría la minería a cielo abierto y el uso de cianuro; y pondría un límite en el uso del agua.

Este proyecto de la nueva ley de minería había sido bloqueado en el 2006 por el presidente del Congreso Nacional y futuro presidente Porfirio Lobo, pero impulsado por la ACD, la cual otra vez estaba esperando la aprobación del congreso para agosto del 2009. No obstante, por presión del grupo de lobby de la minería ANAMIMH , el presidente Zelaya destituyó de su cargo al secretario de estado de la Secretaría de Recursos Naturales y Ambiente, quien estaba abierto al diálogo con el movimiento (Monje, 2013).

Independientemente de la cuestión de sí la propuesta de la nueva ley de minería hubiera sido aprobada, el golpe de estado que acabó con la presidencia de Zelaya también echó atrás los avances del movimiento antiminero. En la crisis política y económica que seguiría, varios donantes internacionales -socios esenciales como proveedores de los recursos necesarios para las movilizaciones del movimiento- se retiraron del país. La suma de estos factores condujo a que la Alianza Cívica fuera desmantelada, y en los seis meses de ínterin del presidente Roberto Micheletti, el Estado comenzó a otorgar nuevas concesiones mineras. No obstante, la redacción de una nueva ley de minería esperaría hasta el 2012.

La ACD perdió su fuerza en el 2009 por la crisis política y porque sus líderes se vieron obligados, por juegos políticos así como amenazas, a abandonar el movimiento. No obstante, las organizaciones integrantes se reorganizaron en la Coalición Nacional de Redes y Organizaciones Ambientales de Honduras (Conroa). Conroa es un plataforma cuyo objetivo principal es oponerse a la minería a cielo abierto y otros megaproyectos (represas hidroeléctricas y plantaciones de palma africana).

El gobierno posgolpe de Porfirio Lobo creyó que la minería era el camino para aliviar la pobreza y pagar la deuda externa y doméstica del Estado. Para este fin, se creó un comité del congreso (Comisión de Minería del Congreso Nacional), con la tarea de buscar admisión a la EITI (Extractive Industries Transparency Initiative) y promover una nueva ley de minería. Como expresó el entonces director de Inhgeomin (Instituto Hondureño de Geología y Minas), Aldo Santos, había un sentido de urgencia y desesperación en el nuevo esfuerzo del gobierno para desarrollar la minería como la primera industria de Honduras:

Si no hay firma con el fondo monetario, ¿de dónde vamos a sacar dinero para pagar la deuda social que el país tiene? Honduras tiene una deuda circulando interna. De más de 23000 millones de lémpiras. Que les debe a proveedores internos. Y según proyecciones del banco central de Honduras y organismos internacionales, Honduras va a llegar ya creo que superamos ya los 2500 millones de dólares de deuda externa. (...) O sea mis hijos, mis nietos, mis bisnietos, están condenados a 
pagar parte de sus ingresos. Dado este panorama, no hay más de donde sacar plata. ¿De dónde pagar esta deuda galopante interna y externa? Es de la minería. Eso es la realidad. (...) ¿Es que de donde más? No hay producción. ¿De dónde más? ¿De dónde más? (A. Santos, comunicación personal, 11 de octubre de 2013).

Para la redacción de la nueva ley de minería (República de Honduras, 2013), Honduras recibió apoyo de expertos asignados por la Cooperación al Desarrollo Internacional Canadiense. El presidente Porfirio "Pepe" Lobo, de origen latifundista, ordenó la socialización de la ley con ambos sectores, el minero y la sociedad civil; esta discutida durante un periodo de seis meses en el 2012. No obstante, representantes del estado expresaron estar contentos con la exitosa socialización de esta nueva ley. Sin embargo, la mesa de diálogo no estableció un consenso entre los diferentes grupos de interés, las organizaciones ambientalistas y otras organizaciones críticas a la minería, las cuales eventualmente abandonaron las negociaciones. Las organizaciones consideraban que no podían firmar una ley previamente redactada y que, además, no incluía su demanda principal: la prohibición del uso de cianuro y la minería a cielo abierto. Como comentó Dr. Almendarez (comunicación personal, 11 de julio de 2013), uno de los líderes de Conroa: "Era una farsa la socialización. La nueva ley solamente reafirma la continuidad de la explotación minera basada en cianuro y en base a cielo abierto. Reproduce el mismo modelo de producción minera".

Un nuevo aspecto de la actual ley es el derecho a la consulta, este se debe realizar para que una compañía pueda proseguir a la fase de explotación, después de la fase de exploración minera. En las palabras del presidente de la Comisión Minera del Congreso Nacional, Donaldo Reyes Avelar, esto es "un hecho bien importante. ¿Quienes deciden si hay minería o no hay minería? Los pueblos. Los municipios. El pueblo que quiere y analiza que puede ser buena la explotación minera en su término municipal crece, y otros allá que dicen que no pues que vivan en su pobreza si quieren" (D. Reyes, comunicación personal, 11 de octubre de 2013).

Sin embargo, la nueva Ley de minería retiene una serie de aspectos controversiales. No hay límite en el número de años de vigencia de una concesión. Ni la minería artesanal y de pequeña escala, ni las actividades de exploración requieren un permiso ambiental (Título XV). La minería artesanal no requiere una concesión, sino que será directamente negociada con la municipalidad (Art. 90). Las compañías mineras están libres de elegir cualquier método de extracción, y tienen permiso para usar agua ilimitada, dentro y fuera la concesión (Art. 53c). No se puede declarar ningún territorio permanentemente libre de minería (Art. 49), y cuando una concesión esté ubicada en varios municipios, solamente un municipio tiene derecho a la consulta (Art. 68). Cuando una comunidad rechaza un proyecto minero en la consulta, su decisión solamente tiene vigencia por tres años (Art. 67). Por último, pero no menos importante, la ley establece una tasa de seguridad de 1/3 parte de las regalías pagadas (de un total de $6 \%$ sobre el valor de exportación), para invertir en la policía, el ejército y la recién creada política militar (Art. 76). Según Pedro Landa, coordinador de Conroa, la tasa no contribuye a la seguridad del pueblo hondureño, pero provee: "seguridad en respaldo a las corporaciones transnacionales. Pero al contrario se van a convertir también en instrumentos 
de mayor represión hacia las comunidades que están dispuestos a defender sus recursos naturales y sus territorios ante la amenaza que representa la empresa minera a las comunidades" (P. Landa, comunicación personal, 20 de junio de 2013).

Analizando el siguiente estudio de caso, parece ser cierto que la tasa de seguridad forja un vínculo financiero directo entre policía, ejército y empresas mineras, lo cual provee a estas instituciones con incentivos adicionales para operar a favor de la compañía.

\section{Caso: movilización y violencia en Nueva Esperanza, Atlántida}

El día 12 de julio del 2012, el empresario Lenir Perez, yerno del oligarca Miguel Facussé3 y propietario de Alutech $^{4}$-una compañía nacional de productos de hierro- obtuvo una concesión minera de 1000 hectáreas después de establecer que la extracción de óxido de hierro sería rentable. La empresa involucrada tiene el nombre de Sociedad Mercantil la Victoria. Hay que notar que Lenir Pérez es una figura de influencia y reputación, como ha resumido un periodista del medio de comunicación independiente Radio Progreso: "si se sabe que él es cuñado de Miguel Facussé, la gente ya tiene miedo. Miguel Facusé es una figura de mucha represión, de dinero, de armas. Se sabe de la situación del Bajo Aguan, de tantos muertos. La gente tiene miedo. Es bien complicado" (Periodista de ERIC-RP, comunicación personal, 25 de octubre de 2013).

La concesión fue otorgada en una región conocida como La Florida, departamento de Atlántida, hogar de 16 comunidades unidas en un solo patronato. La comunidad local fue informada -no consultada- de sus intenciones. El estudio de impacto ambiental fue aprobado por la municipalidad de Tela. Algunos líderes de organizaciones populares afirman que el alcalde de Tela recibió unos 7 millones de Lempiras (350 000 US\$) por su apoyo al proyecto.

Las comunidades de La Florida, a través de ERIC-Radio Progreso, anunciaron su oposición al proyecto minero. Líderes locales afirman que, como respuesta a la oposición de la comunidad, un "trabajador de salud" fue colocado en la zona por la empresa, y utilizado como promotor de la mina, prometiendo empleos, motocicletas, así como salarios de 9000 lempiras (450 US\$) a los jóvenes. Así, varios de ellos se comenzaron a identificar como potenciales trabajadores de la mina, creando un conflicto interno dentro la comunidad. "Andan amenazando a sus propias familias. Es bien duro, es bien duro", comentó un entrevistado. (comunicación personal, 25 de octubre de 2013).

3 Facussé fallecido en el 2015, era en ese entonces propietario de la corporación Dinant (palma africana y derivados). Conocido por su involucramiento en el conflicto de tierras en la región de Bajo Aguán, el cual ha cobrado las vidas de más de cien campesinos.

4 Teniendo en cuenta las acciones del negocio de Lenir Perez, la visión de Alutech se puede leer como ironía dado que reza: "establecernos como la mejor industria transformadora de metal en Centroamérica, en su responsabilidad social tanto como la calidad y excelencia de sus productos" (Alutech, 2014).

Cuadernos de Antropología 2016, 26(2), 69-89 / ISNN 2215-356X

http://revistas.ucr.ac.cr/index.php/antropologia 
Cuando la compañía trataba de trasladar maquinaria pesada al territorio concesionado, la comunidad era alertada e impedía el acceso poniendo un bloqueo en la carretera. Sin embargo, la policía intervino y ordenó la remoción del bloqueo, ya que la comunidad estaba violando el derecho de libre paso de los vehículos de la compañía. Después de terminar el bloqueo a disparos, se estableció un puesto policial permanente con tres policiales regulares y cuatro oficiales de Los Cobra ${ }^{5}$ en un pueblo de 150 habitantes.

En respuesta a la ocupación policial, el patronato de La Florida buscaba el apoyo de Movimiento Amplio por la Dignidad y Justicia (MADJ) - un movimiento social fuerte en la región. El MADJ fue impulsado por cuatro fiscales del Ministerio Público, que comenzaron una huelga de hambre en el 2008 para protestar en contra la corrupción sistémica dentro del ministerio; esta huelga fue repetida en varias partes del país, dándole fuerza al MADJ. En los siguientes años turbulentos, el MADJ tuvo un papel importante en las protestas en contra del golpe de estado y en la formación del Frente Nacional de Resistencia Popular (FNRP).

El MADJ, junto con el Movimiento Ambiental de Atlántida (MAA) y apoyado por un grupo de sacerdotes locales, organizó capacitaciones con la comunidad sobre los impactos de la minería y la forma de detenerla con un proceso legal. Miembros de la comunidad viajaron al Valle de Siria, San Andrés, y El Mochito, en Las Vegas 6 , Santa Bárbara, para enfrentar las comunidades afectadas por la minería y verificar sus impactos. En respuesta a la oposición al proyecto minero, fue amenazado a muerte el presidente del patronato de La Florida y su familia, así como los sacerdotes involucrados. El siguiente mensaje de texto es un ejemplo: "bamos a pedacear a bos i monja" . Como consecuencia de las amenazas, los sacerdotes se vieron forzados a retirarse del área.

Periodistas españoles, invitados por ERIC ${ }^{8}$-Radio Progreso-- visitaron la comunidad para documentar su lucha. La situación revivió memorias sobre un conflicto de los años 90, en el cual siete miembros de la comunidad de La Florida fueron asesinados impunemente por resistirse a los acaparamientos de tierras por parte de los latifundistas. De ahí el nombre del documental sobre el conflicto minero de Nueva Esperanza: "Honduras. Mártires de la tierra". Sin embargo, el documental no ayudó a resolver la situación, puesto que fue creado antes de la escalada final del conflicto. Como comentó un sacerdote en una entrevista hecha por un periodista español: "aquí tenemos en Honduras experiencias muy tristes de contaminación, de gente enferma con cáncer, con enfermedades en la piel, por la contaminación de sus aguas de sus ríos. Son situaciones de que no ha habido forma de que el gobierno controle" (entrevista en documental "Honduras. Mártires de la tierra" [Flor et al., 2013]). Específicamente, se refiere a los daños dejados en el Valle de Siria

5 Las Cobras son fuerzas especiales de la policía, entrenadas por los SWAT de EE.UU.

6 La mina de El Mochito ya está en operación por 50 años y no opera a cielo abierto; por lo tanto, nunca ha sido objeto de fuerte oposición por el movimiento antiminero.

7 El mensaje fue citado con redacción y ortografía original. Significa "vamos a cortar a vos y el monje en pedazos".

8 Equipo de reflexión, investigación y comunicación.

Cuadernos de Antropología 2016, 26(2), 69-89 / ISNN 2215-356X

http://revistas.ucr.ac.cr/index.php/antropologia 
por la operación de Goldcorp.

La diócesis de Tela también invitó a Carlos Amador, vocero del Comité Ambiental del Valle de Siria (CAVS), así como a otros habitantes del Valle de Siria, para asistir a un encuentro en Nueva Esperanza. Como lo explicado por Carlos Amador, ahora el CAVS tiene un papel clave en el proceso de concientización de las comunidades: "somos campesinos. Campesinos con la voluntad de lucha, de cuidar de proteger. Hoy en el día, estamos generando una voz para que las comunidades conozcan, para que no permitan que las empresas entren en las comunidades" (C. Amador, comuniación personal, 15 de junio de 2013).

El obispo de Tela también se involucró en el asunto y trató de mediar, organizando reuniones entre la comunidad, la empresa y representantes de Inhgeomin. En un encuentro en mayo del 2013, el director de esta entidadafirmó que la comunidad no necesitaba preocuparse, ya que la compañía solamente estaba explorando - no explotando. A menudo, se escucha este argumento en defensa de un proyecto minero, pero esto no es creíble para las comunidades y actores antimineros: se razona que ninguna compañía entra en actividades de exploración si no hay interés de seguir explotando cuando los resultados sean positivos. Por lo tanto, a pesar de la intención de Inhgeomin de convencer a la población de mantener la tranquilidad, el resultado de estas reuniones era claro: la comunidad rechazaba la mina, no estaba dispuesta a perder su tierra y arriesgar la contaminación de su agua.

Carlos Amador del Comité Ambiental de Valle de Siria aseguró en su discurso realizado en mayo del 2013 para la comunidad de Nueva Esperanza: "el hecho que andemos con un sombrero, con una gorra, o con zapatos humildes o ropas humildes no es que no sabemos defender lo que Dios nos ha dado. ¿Y qué Dios nos ha dado? La naturaleza [.... Pero en Honduras es un pecado defender la vida" (C. Amador en "Honduras. Mártires de la tierra" [Flor et al., 2013])

En el discurso social antiminero tiene fuerza la idea de que en Honduras es un pecado defender la vida: aquellos que defienden su agua, territorio y modo de vida están expuestos a un castigo. Amador puede relacionarlo a sus propias experiencias de persecución por su defensa del territorio. Sus palabras también predijeron lo que iba a pasar a los habitantes de Nueva Esperanza: métodos violentos fueron usados para "convencer" a la comunidad de otra manera.

En el trabajo de campo se informó de dos acontecimientos que ilustran la represión. En una ocasión, la policía le disparó a un campesino de 79 años. Después de denunciar los actos ilegales de los responsables, las autoridades transfirieron a los culpables, reemplazándolos con otros. Guardias armadas, según entrevistados, empleados por la empresa de seguridad Orión ${ }^{9}$, fueron colocados en el pueblo para prevenir el acceso de la comunidad al sitio minero. Los guardias de seguridad de la empresa también entraron a la aldea en la

9 Orión está implicada en secuestros, tortura y asesinatos de campesinos en el Bajo Aguan. 
noche, disparando al aire con sus armas automáticas ${ }^{10}$.

En respuesta a las hostilidades, dos observadores internacionales de derechos humanos del Proyecto de Acompañamiento Internacional de Honduras (PROAH), por sus conexiones con el MADJ, se mudaron a la aldea para quedarse con una familia local. Sin embargo, fueron capturados por 50 guardias y trabajadores de la mina, armados con machetes y armas de fuego. Además, fueron interrogados, llevados a un pueblo fuera de la región, y liberados bajo la amenaza de que iban a ser asesinados si regresaban a Nueva Esperanza. Unas horas después, los guardias dispararon al hombre que había dado alojamiento a los observadores. Él y su familia lograron escapar de la comunidad (PROAH, 2013). Desde ese evento, varias personas han sido desplazadas por el grupo armado, y activistas del MADJ reportan en una entrevista que la escuela local tuvo que suspender las clases, ya que el maestro tuvo que huir.

En el extenso reportaje sobre el conflicto minero, la revista mensual de ERIC-Radio Progreso escribió en su edición de octubre del 2013 (Guevara, 2013) que: "la petición de los niños y padres de familia es que el Empresario Lenir Pérez retire a los hombres armados del sector, pues viven sembrando el terror e intimidando a toda aquella persona que no está de acuerdo con el proyecto de muerte que impulsa el empresario" (p. 4).

Este acto público de nombrar y avergonzar el proyecto de muerte tiene un doble sentido. Primero, es una referencia al carácter de cielo abierto de la mina, visto como una fuente de contaminación del agua potable de la comunidad. Segundo, el proyecto instalado por la empresa minera se puede considerar un proyecto de muerte por su uso extremo de terror como medida para facilitar la continuación del proyecto minero.

Se reportaron estos actos de violencia e intimidación al Ministerio Público e Inhgeomin. Sin embargo, en el periodo del trabajo de campo no se pudo ver actuación alguna del Ministerio Público ni la policía (a pesar de su presencia permanente en el pueblo); y los oficiales de Inhgeomin responden al investigador que no les corresponde resolver conflictos sociales. En una entrevista con periodistas españoles que documentaron el conflicto minero, un empleado de una estación de radio local -con vínculos con Radio Progreso, comentó que "es irónico porque, se supone que la policía es para dar seguridad, pero cuando uno mira la policía no se siente seguridad, más bien se siente temor. Temor porque muchos de ellos son cómplices de los delincuentes" (Flor et al., 2013).

La amenaza constante planteada por los empleados de la empresa minera y la fuerza policial dio como resultado una situación sostenida de temor. Eventualmente, los pobladores se sintieron forzados a vender su tierra. Aprovechándose de la situación, a mediados del 2013, el empresario Lenír Peréz comenzó a comprar las tierras que rodean la concesión minera. Algunos campesinos afirmaron que la cantidad de tierra com-

10 La posesión de armas de fuego es legal en Honduras, pero las armas automáticas están prohibidas para los civiles. 
prada fue de, aproximadamente, 33 manzanas (23 hectáreas). Los habitantes reportaron ante ERIC-Radio Progreso haber vendido su tierra por temor.

Sin embargo, el proyecto minero no logró establecerse en el territorio. Bajo presión internacional, la Fiscalía procedió a procesar al jefe de seguridad de la empresa minera, quien fue condenado el día 18 de noviembre del 2014 por varios delitos como privación de libertad y coacciones (MADJ, 2014a). Por razones desconocidas, probablemente por la falta de rentabilidad del proyecto, la mina fue abandonada en diciembre del 2014.

Nueva Esperanza representa un caso en el cual una comunidad rural organizada se resistió a un proyecto y buscó ayuda de otros actores, notablemente el MADJ y la Iglesia Católica. La diócesis de Tela, MADJ y ERIC-Radio Progreso tuvieron un papel clave en el empoderamiento de la comunidad, tomando una serie de pasos: capacitaciones sobre la ley de minería, viajes a otras comunidades afectadas por la minería, y acompañamiento internacional. ERIC-Radio Progreso publicó artículos sobre la situación (Radio Progreso, 2014), MADJ subió artículos a internet en inglés y español (MADJ, 2014b) y se creó una página de Facebook de Nueva Esperanza (Nueva Esperanza Tela - Página Oficial), dedicada a la defensa de la comunidad y sus recursos naturales. Una periodista de Radio Progreso concluyó que: "ha sido un proceso amplio, en la cual la iglesia católica, es decir, los movimientos ambientalistas, el movimiento amplio, y otros sectores han estado involucrado en el sentido de pretender darle elementos a la población para que tengan esa autodeterminación" (J. Ávila, comunicación personal, 25 de octubre del 2013).

Con tanta atención a nivel nacional e internacional; así como el derecho legal de la comunidad de decir no a la mina, es inquietante notar que la represión no disminuyó, sino que empeoro al escalar del proyecto. La única respuesta por parte de las autoridades fue la instalación de un puesto policial -los policías abrieron fuego contra los pobladores en varias ocasiones. Queda claro que la policía no estaba presente para preservar el orden, sino para proteger a la compañía minera. La policía empleó la fuerza como medida para garantizar "el derecho de libre acceso" a una instalación minera, y permitió a la empresa utilizar guardias armadas con armas automáticas para prohibir el acceso de las personas de la comunidad. El caso indica que la falta de respuesta o complicidad de las autoridades da mucho espacio a una compañía para manipular el proceso de consulta (o negarla). En tales condiciones de impunidad, un artículo único en la ley de minería no hace nada para garantizar la autodeterminación.

\section{Movilizando la base frente la industria minera}

En la Honduras posgolpe, las perspectivas del movimiento antiminero y el gobierno central son tan extremadamente diferentes que ya no se cree que el diálogo pueda ser fructífero. Por lo tanto, la estrategia del movimiento ha cambiado su enfoque, desde movilizaciones a nivel nacional para presionar el gobierno central, hasta la organización de movilizaciones comunitarias con el fin de presionar a la alcaldía y declarar 
al municipio libre de minería. De igual forma, activistas antimineros identifican a los líderes comunitarios, notablemente los del patronato y juntas de agua, para invitarlos a capacitaciones y encuentros informativos.

En las capacitaciones organizadas, se mostró el documental "Honduras. Mártires de la tierra" (Flor et al., 2013). sobre la lucha comunitaria en Nueva Esperanza. De igual forma, se mostraron otros videos, con actores y cantantes argentinos y colombianos proclamando estar en contra de la minería a cielo abierto, así como un documental sobre el caso de la mina de Crucitas en Costa Rica ${ }^{11}$. Además, se ha criticado la demolición de las iglesias y cementerios para la expansión de las minas a cielo abierto, se cuestiona la legitimidad de la cantidad de regalías pagadas y la capacidad de una compañía de generar empleo sostenible; y se han generado dudas sobre la capacidad del Estado de controlar si la empresa explota en secreto otros metales, además que los reportados. Asimismo, se enseña sobre las causas y efectos del cambio climático y la contribución de la minería a dicho proceso. Sin embargo, de todos estos argumentos, ninguno es tan eficaz como el argumento de que la minería es una amenaza para el agua y a vida -con el claro ejemplo de los impactos sobre la salud en la población del Valle de Siria. Se enseña a los líderes comunitarios que la minería, notablemente la minería a cielo abierto, seca las fuentes de agua y las contamina: "sin agua, no hay vida (...) nada vale más que el agua de las comunidades" (Anónimo, comunicación personal, 29 de octubre de 2013), como acostumbra decir una activista durante una capacitación comunitaria.

La frase "el agua vale más que el oro" se ha convertido en la ideología principal del movimiento, y resuena con la realidad vivida en la Honduras rural: las comunidades rurales tienen una dependencia fuerte en los recursos naturales para su sobrevivencia. En el área rural de Honduras, la mayoría de hogares no tiene acceso a servicios de agua corriente (Herrera, 2013), lo cual significa que estos hogares dependen, entre otros, de los ríos y quebradas locales para su consumo y la producción agrícola.

Durante una visita del autor a una comunidad $\mathrm{Pech}^{12}$, en noviembre del 2013, para alertarla que un hacendado cercano está negociando la venta de su terreno con una empresa minera, su primera reacción es de incredulidad: "no se puede por la razón de que es una zona boscosa. Es una zona donde fluyen las fuentes de agua. ¿Cómo va a ser que se acepte esto? ¡Es imposible!” (Anónimo, comunicación personal, 8 de octubre de 2013). La comunidad está bien consciente de sus derechos como pueblo indígena. Cierto, no se ha otorgado ninguna concesión minera en territorio Pech, pero el agua que será afectada por la explotación río arriba fluye por su territorio. Un campesino en un pueblo adyacente a la comunidad Pech se refirió al peligro que esto significa: "Va a matar (...) como una medicina letal de muerte lenta. Si nos quietan el agua, es como si nos quieten nuestro oxigeno" (Anónimo, comunicación personal, 8 de octubre de 2013).

Al escribir sobre los conflictos mineros en la región andina, Budds y Hinojosa (2012) concluyen que el

11 Los movimientos antimineros del continente están interconectados y tienen la capacidad de intercambiar información rápidamente. Tienen redes con países vecinos, y el flujo de información está facilitado por el trabajo de organizaciones como OCMAL (Observatorio de Conflictos Mineros de América Latina) y el TLAA (Tribunal Latinoamericana de Agua).

12 Pueblo indígena que habita en comunidades rurales ubicadas en el noreste de Honduras.

Cuadernos de Antropología 2016, 26(2), 69-89 / ISNN 2215-356X

http://revistas.ucr.ac.cr/index.php/antropologia 
agua comúnmente tiene un papel clave en los conflictos mineros. Citando a Swyngedouw (2004) mencionan que: "el agua es un elemento 'hibrido', que captura y encarna procesos que al mismo tiempo son materiales, discursivos y simbólicos" (Budds y Hinojosa, 2012, p. 51). Esto es igualmente aplicable para Honduras: el agua es una necesidad humana inalienable para el consumo y la producción agrícola, convirtiéndose así la minería en un competidor de la agricultura local, una amenaza para el sustento campesino, y una amenaza para el suministro de agua de los asentamientos cercanos. Mientras los asuntos estrictamente territoriales son de poco interés de las comunidades cercanas o urbanas (Bebbington, Bebbington y Bury, 2011), el valor simbólico del agua como requisito de la vida se convierte en un instrumento discursivo poderoso en la movilización de comunidades enteras, sobre todo rurales, pero también urbanas, contra la minería.

En la nueva estrategia del movimiento antiminero, se busca declarar libre de minería los municipios a través de acciones preventivas. Eso quiere decir, a través de movilizaciones a nivel municipal; en municipios donde aún no hay presencia de la industria minera, las comunidades exigen la organización de un cabildo abierto, donde el pueblo se pronuncia y presiona al alcalde para respaldar su decisión. Esto ha mostrado ser una estrategia exitosa: a finales de 2015, aproximadamente 25 municipios habían sido declarados libre de minería, un número que está creciendo anualmente ${ }^{13}$. Sin embargo, hay que notar que aún está por verse si la acción de declarar una municipalidad libre de minería tiene validez legal. Una declaración notable es la del municipio de El Negrito, Yoro, después de una movilización de aproximadamente 10000 personas acompañados por el MADJ.

\section{Conclusiones}

Honduras presenta un caso donde la expansión de la industria minera genera una conflictividad social considerable. Todos los aspectos asociados con el proceso de "posesión por desposesión" (Harvey, 2004) fueron encontrados; entre otros, la expulsión forzosa de comunidades campesinas, la supresión del derecho a los bienes comunes, y la supresión de formas de producción alternativas. La defensa del territorio -un marco discursivo ampliamente usado por las comunidades involucradas en la oposición a la minería-es una respuesta a los métodos agresivos de acaparamiento de tierras por parte de las empresas mineras, así como las memorias invocadas de las luchas pasadas de estas comunidades sobre su acceso a la tierra y los recursos naturales, luchas que han cobrado las vidas de pobladores que se recuerdan como mártires. Asimismo, el temor por la contaminación del agua contribuye al punto de vista de que la entrada de una compañía minera viola la integridad territorial de estas comunidades.

Harvey (2004) ha señalado que en el proceso de posesión por desposesión, el estado "juega un rol crucial al respaldar y promover estos procesos" (p. 113). Como ha mostrado el caso de Nueva Esperanza, la

13 Incluye Santa Bárbara, Atima, Colinas y San Francisco de Ojuera en Sánta Barbara; Chinaclas y San José de la Paz en La Paz; Belen Gualcho en Ocotepeque; Yorito en Yoro; Juticalpa y Olancho en Olancho; Danlí and Teupasenti en El Paraíso; Jesús de Otoro en Intibuca; y Saba en Colón (Asonog, 2014).

Cuadernos de Antropología 2016, 26(2), 69-89 / ISNN 2215-356X

http://revistas.ucr.ac.cr/index.php/antropologia 
industria minera se ve beneficiada de la disposición de diferentes instituciones del Estado. Sin embargo, el argumento de este autor que señala que el Estado tiene un monopolio a la violencia necesita ser adaptada para el caso hondureño: el poder es oligopólico, compartido entre diferentes núcleos de poder como grandes empresas y narcocarteles. De esta manera, el complejo extractivista, como configuración de diferentes instituciones pro-mineras, tiene a su disposición una gama de diferentes métodos para expandir la frontera extractiva: clausurar el territorio concesionado, criminalizar la protesta social, ofrecer sobornos para causar divisiones internas, utilizar la amenaza y el uso de terror, en un marco de impunidad en cuanto a las violaciones cometidas por las compañías. Cuando las instituciones del Estado no garantizan un proceso justo y fracasan en la prevención y el manejo de estos conflictos, y cuando las empresas son capaces de utilizar la amenaza y la violencia con impunidad, movilizar a nuevos actores y escalar la protesta hasta el nivel nacional o internacional puede ser la única manera para que una comunidad gane la lucha. En este proceso, las organizaciones del movimiento antiminero funcionan como catalizadores, usan su red transnacional para conectar a las comunidades comprometidas en la defensa del territorio, con organizaciones internacionales de solidaridad y derechos humanos.

El movimiento no le da mayor peso al proceso de consulta establecido en la Ley de Minería (República de Honduras, 2013). Como alternativa, se busca capacitar a los líderes comunitarios para que organicen cabildos abiertos con el fin de declarar el municipio libre de minería. Esto puede explicarse porque el movimiento no tiene confianza en el sistema oficial. Como se vio en el estudio de caso, la consulta para la fase de explotación no es ninguna salvaguardia para un proceso de toma de decisiones libre, previa e informada. Paradójicamente, tanto la ley como la impunidad favorecen a la industria minera, permitiendo la apropiación de tierras y la expansión de la frontera de recursos. El cabildo abierto como medida preventiva, promovido por el movimiento antiminero, tiene una diferencia crucial con la consulta establecida por ley y es que esta establece que la consulta oficial se lleve a cabo bajo control de la industria minera, mientras que las comunidades tienen mayor influencia sobre los resultados del referéndum preventivo.

Parcialmente, se puede atribuir la falla de consulta oficial al hecho de que fue establecida para la fase de explotación, en vez de la fase anterior de exploración, por el hecho de que la exploración minera requiere una inversión significante en tiempo y dinero. Si la consulta estuviera prevista para iniciar la fase de exploración (la primera fase del proyecto), no habría una pérdida financiera si una comunidad rechazara el proyecto. Por ello, es más probable que la empresa recurra a medidas ilegales cuando corre el riesgo de perder su inversión. En pocas palabras, esta disposición crea espacio para la manipulación de la consulta. Además, las divisiones comunitarias internas - causadas o agravadas por la entrada de una compañía minera y la oposición de las organizaciones- en el transcurso de los eventos afectan profundamente la resistencia a la minería y pueden escalar a un nivel fatal.

Ahora, ¿puede este conflicto social ser un precursor necesario para lograr un cambio progresivo social e institucional, como sugerido por Bebbington y Valencia en el 2007? Para el movimiento antiminero en Honduras, las oportunidades políticas eran considerablemente más altas antes del golpe de estado. Un 
progreso institucional probablemente podría darse a largo plazo, ya que es casi imposible dialogar con el actual gobierno. El movimiento responde a esta situación pasando por alto al gobierno central a través de la movilización al nivel comunitario, pero, a su vez, el Estado podría tratar de imponer sus políticas con mayor represión cada vez -los eventos futuros lo dirán. Será difícil para el movimiento incidir y lograr un cambio institucional mientras esté dedicado a (a veces literalmente) la defensa de territorio: acompañando luchas comunitarias y cabildos abiertos para frenar la expansión de la frontera extractivista.

En el caso hondureño, el cambio institucional necesita ir precedido por un cambio social -el que ya lentamente está ocurriendo Los movimientos sociales no solamente movilizan a las comunidades con el fin de reclamar derechos de tierras o declarar municipios libre de minería: son vehículos de empoderamiento de los individuos y las comunidades participantes para ejercer sus derechos como ciudadanos y para fortalecer su capacidad de participar colectivamente en la política de base, para incidir en la obtención de sus derechos. En este sentido, las movilizaciones también representan la formación para la solidaridad (Melucci y Avitzer, 2000) y la expresión de autonomía (Zibechi, 2003). En la medida que la brecha entre la práctica institucional y las necesidades de la sociedad civil sigue existiendo (o creciendo) en Honduras, en esa medida las comunidades estarán cada vez más conscientes de sus derechos y los movimientos sociales y las movilizaciones ciudadanas van a seguir jugando un papel importante en el futuro previsible.

\section{Referencias bibliográficas}

Acosta, A. (2011). Extractivismo y neoextractivismo: dos caras de la misma maldición. En M. Lang y D. Mokrani (comp.), Más allá del desarrollo (pp. 83-118). Quito: Editorial El Conejo.

Alutech. (2014). Alutech. Recuperado de http://www.alutech.hn

Asociación de Organizaciones no Gubernamentales (Asonog). (2014). Declarando municipios libre de minería. Recuperado de http://mnigrhonduras.org/wp-content/uploads/2014/06/Sistematizacion-deMunicipios-libres-de-Minerria.pdf

Bebbington, A. (2012). Extractive industries, iocio-environmental conflicts, and political economic transformations in Andean America. En A. Bebbington (ed.), Extractive industries, social conflict and economic development: evidence from South America, (pp. 3-26). London: Routledge.

Bebbington, A., Bebbington, D. H. y Bury, J. (2011). Federating and defending: water, territory and extraction in the Andes. En R. Boelens, D. Getches y A. Guevara-Gil (eds), Out of the mainstream: water rights, politics, and identity (pp. 307-327). London: Earthscan.

Bebbington, A., Hinojosa, L., Bebbington, D. H., Burneo, M. L. y X. Warnaars. (2008). Contention and ambiguity: mining and the possibilities of development. Development and Change, 39(6), 965-992.

Bebbington, A. y Valencia, L. H. (2007). Conclusiones: minería, neoliberalisación, y reterritorialización en el desarrollo rural. En A. Bebbington (ed.), Minería, movimientos sociales y respuestas campesinas: una ecología política de transformaciones territoriales, (pp. 281-313). Lima: IEP y Cepes.

Bianchini, F. (2006). Estudio técnico. Contaminación de agua en el área de explotación minera del pro- 
yecto San Martín, en el Valle de Siria y repercusiones sobre la salud humana. Manuscrito inédito. Recuperado de http://miningwatch.ca/sites/default/files/Valle_de_Siria-Glamis_Gold_0.pdf

Budds, J., y Hinojosa, L. (2012). Las industrias extractivas y los paisajes hídricos en transición en los países andinos: análisis de la gobernanza de recursos y formación de territorios en Perú. En R Boelens, E. Isch y F. Peña (eds), Justicia hídrica. Agua, injusticia y conflictos, (pp. 45-61). Lima: Fondo Editorial, Pontificia Universidad Católica del Perú, Justicia Hídrica, Centro Bartolomé de Las Casas, Instituto de Estudios Peruanos.

Coronel, O. (2013). La desconfianza y el miedo: el caso del conflicto hídrico entre Hualla y la Southern Copper Corporation. En A. Arroyo y R. Boelens (eds), Aguas robadas. Despojo hídrico y movilización social, (pp. 207-224). Quito: Justicia Hídrica, ABYA YALA YALA, Instituto de Estudios Peruanos.

Flor, S., González, M., Manteca, M. (Productores) y Del Olmo, J. (Director) (2013). Honduras: Mártires de la Tierra [Documental]. España: Pueblo de Dios TVE. Recuperado de http://www.movimientom4. org/2013/07/video-honduras-martires-de-la-tierra/

Equipo de Reflexión, Investigación y Comunicación (ERIC) y Radio Progreso. (2014). Estado hondureño incumple medidas de protección dictadas por la CIDH. Recuperado de http://radioprogresohn. net/index.php/comunicaciones/noticias/item/981-estado-hondure\%C3\%B1o-incumple-medidas-deprotecci $\% \mathrm{C} 3 \% \mathrm{~B} 3 n$-dictadas-por-la-cidh

Eriksen, T. H. (2004). What is Anthropology?. London: Pluto Press, .

Global Witness. (2015). How many more? 2014's Deadly environment: the killing and intimidation of environmental and land activists, with a spotlight on Honduras (Report April 20, 2015). Recuperado de https://www.globalwitness.org/campaigns/environmental-activists/how-many-more/

Golafshani, N. (2003). Understanding reliability and validity in qualitative research. The Qualitative Report, 8(4), pp. 597-607.

Gordon, T. y Webber, J. R. (2011). Canada and the Honduran coup. Bulletin of Latin American Research, $30(3)$, pp. 328-243.

Guevara, L. (20 de septiembre de 2013). Niños víctimas del conflicto minero. aMECATE CORTO, edición 203, p. 4. Nacionales. Recuperado de http://www.radioprogresohn.net/index.php/amecate-corto/ periodico-mensual/item/693-amecate-corto-\%7C-octubre-2013

Harvey, D. (2004). El “nuevo" imperialismo: acumulación por desposesión. Socialist register. Recuperado de http://socialistregister.com/index.php/srv/article/viewFile/14997/11983

Heldens, J. y Reysoo, F. (2005). De kunst van het interviewen. Reflecties op het interview met een guide. Kwalon - tijdschrift voor kwalitatief onderzoek in Nederland, 10(3), pp. 106-121.

Herrera, F. (2013). La mina San Martín en el valle de Siria. Exploración, explotación y cierre: impactos y consecuencias. Tegucigalpa: IDAMHO Gráficos. Informe ejecutivo.

Joker, W. M. (2004). Changing places: environment, development and social change in rural Honduras. Durham North Carolina: Carolina Academic Press.

Lichterman, P. (1998). What do movements mean? The value of participant-observation. Qualitative Sociology, 21(4), pp. 401-418.

Monge, E. (coord.). (2013). Report of the Commission of Truth. The voice of the greatest authority is that 
of the victims. Tegucigalpa: Commission of Truth.

Moore, J. (2012). Canada's mining indusry \& corporate social responsibility. The Community Networks. Recuperado de https:/communitynetworks.wordpress.com/2012/10/03/canadas-miningindustry-corporate-social-responsibility-part-1/

Movimiento Amplio por la Dignidad y la Justicia (MADJ). (18 de noviembre de 2014a). Ex jefe seguridad de Empresa Minerales la Victoria condenado a prisión por violación a derechos humanos. Honduprensa [Comentario en foro en línea]. Recuperado de https://honduprensa.wordpress.com/2014/11/18/ ex-jefe-seguridad-de-empresa-minerales-la-victoria-condenado-a-prision-por-violacion-a-derechoshumanos/

Movimiento Amplio por la Dignidad y la Justicia (MADJ). (3 de septiembre de 2014b). Comunidades en tela, Atlántida fueron declaradas productoras de agua y libre de exploraciones y explotaciones mineras [Comentario en foro en línea]. Recuperado de http://movimientoampliodignidadyjusticia. blogspot.nl/2014/09/comunidades-en-tela-atlantida-fueron.html

Peluso, N. L., y Lund, C. (2011). New frontiers of land control: introduction. The Journal of Peasant Studies, 38(4), pp. 667-681.

Perreault, T. (2013). ¿Despojo por acumulación? Minería, agua y justicia social en el altiplano boliviano. En A. Arroyo y R. Boelens (eds), Aguas robadas. Despojo hídrico y movilización social, (pp. 187205). Quito: Justicia Hídrica, ABYA YALA, Instituto de Estudios Peruanos.

Proyecto de Acompañamiento Internacional en Honduras (PROAH). (2013). Proyecto de minería en La Nueva Esperanza: Escalada alarmante de intimidaciones dirigidas a la comunidad. Proyecto de Acompañamiento Internacional en Honduras. Recuperado de https://proah.wordpress.com/2013/06/20/ proyecto-de-mineria-en-la-nueva-esperanza-escalada-alarmante-de-intimidaciones-dirigidas-a-lacomunidad

Radio Progreso. (2014). Estado hondureño incumple medidas de protección dictadas por la CIDH. Radio Progreso. Recuperado de http://radioprogresohn.net/index.php/comunicaciones/noticias/item/981estado-hondure $\% \mathrm{C} 3 \% \mathrm{~B} 1 \mathrm{o}$-incumple-medidas-de-protecci\%C3\%B3n-dictadas-por-la-cidh

República de Honduras. (1999). Decreto No. 292-98. Ley general de minería. Tegucigalpa: La Gaceta, Diario oficial de la República de Honduras.

República de Honduras, (2013). Ley General de Minería. Tegucigalpa: La Gaceta, Diario Oficial de la Republica de Honduras.

Rights Action. (2014). Brutal public murder of anti-mining, community and environmental defender in Honduras. Rights Action. Recuperado de http://www.rightsaction.org/action-content/brutal-publicmurder-anti-mining-community-and-environmental-defender-honduras

Sluka, J. A. (1990). Participant observation in violent social contexts. Human Organisation, 49(2), pp. 114125.

Sosa, M. (2012). La influencia de la gran minería en Cajamarca y Apurímac, Perú: Acumulación por despojo y conflictos por el agua. En: E. Isch, R. Boelens, R. y F. Peña (eds), Agua, injusticia y conflictos (pp. 63-80). Lima: Fondo Editorial, Pontificia Universidad Católica del Perú, Justicia Hídrica, Centro Bartolomé de Las Casas, Instituto de Estudios Peruanos. 
Svampa, M. (2011). Extractivismo neo desarrollista y movimientos sociales: ¿Un giro eco-territorial hacia nuevas alternativas?. En M. Lang y D. Mokrani (comp.), Más allá del desarrollo, (pp. 185-218). Quito: Editorial El Conejo.

Touraine, A. (2004). On the frontier of social movements. Current Sociology, 52(4), pp. 717-725.

Van Maanen, J. (1988). Tales of the field: on writing Ethnography. Chicago: The University of Chicago Press.

Watts, M. y Peluso, N. (2014). Resource violence. En C. Death (ed.), Critical environmental politics (pp. 184-197). Londres: Routledge.

Yagenova, S. M. (coord..). (2010). Los movimientos sociales y el poder: concepciones, luchas y construcción de contrahegemonía. Guatemala: Flacso, Diakonia.

Zibechi, R. (2003). Los movimientos sociales latinoamericanos: tendencias y desafíos. Observatorio Social de América Latina, 9, pp. 185-188. 